\title{
A critical study of fuzzy logic systems and its applications
}

\author{
Deepak Sharma \\ Research Scholar-Computer science \& System \\ studies, MEWAR UNIVERSITY, Rajasthan
}

\author{
Sohan Garg \\ Director-Sir Chhoturam institute of eng. \& \\ Technology, CCSU Campus, Meerut
}

\begin{abstract}
The idea of fuzzy logic is based close to the human reasoning and regular exercises. It presents predicates which are available in nature and like those either enormous or little. This hypothesis copies human brain science in the matter of how a man settles on the choice speedier. Fuzzy logic is a superset of ordinary (Boolean) logic that has been stretched out to deal with the idea of halfway truth - truth esteems between "totally obvious" and "totally false". It can be actualized in equipment, programming, or a mix of both. It can be incorporated with anything from little, hand-held items to vast modernized process control frameworks.
\end{abstract}

\section{INTRODUCTION}

There are numerous misguided judgments about fuzzy logic. In the first place, fuzzy logic isn't fuzzy. In vast measure, fuzzy logic is exact. Another wellspring of perplexity is the duality of significance of fuzzy logic. In a thin sense, fuzzy logic is a logical framework. Be that as it may, in significantly more extensive sense which is in overwhelming use today, fuzzy logic, or FL for short, is substantially more than a logical framework. Fuzzy Logic gives a straightforward method to land at a clear conclusion in light of unclear, uncertain, loose, uproarious, or missing info data. It is a sort of logic that perceives more than basic genuine and false esteems. With fuzzy logic, suggestions can be spoken to with degrees of honesty and misrepresentation. For instance, the announcement, today is radiant, may be $100 \%$ valid if there are no mists, $80 \%$ genuine if there are a couple of mists, half obvious if it's cloudy and $0 \%$ genuine in the event that it rains throughout the day. Fuzzy logic has turned out to be especially valuable in master framework and other manmade brainpower applications. It is likewise utilized as a part of some spell checkers to propose a rundown of plausible words to supplant an incorrectly spelled one. It was presented by Dr. Lotfi Zadeh of a teacher at the University of California at Berkley in the 1960's as a way to show the vulnerability of regular dialect. He says that as opposed to viewing fuzzy hypothesis as a solitary hypothesis, we should respect the procedure of 'fuzzification" as an approach to sum up ANY particular hypothesis from a fresh (discrete) to a persistent (fuzzy) frame. In this manner as of late scientists have additionally presented "fuzzy analytics", "fuzzy differential conditions" et cetera.

\section{LITERATURE REVIEW:}

The birth and the development of fuzzy logic is described by the pioneer Zadeh, and the best in class following a quarter century of fuzzy frameworks can be found in an aggregate work altered by Klir. General medications of fuzzy set hypothesis, fuzzy logic, and fuzzy frameworks can be found in a few handbooks. Wang et al. (1995) propose a model to research the wellbeing of building frameworks which coordinates the fuzzy sets hypothesis with evidential thinking. Their approach enables the expert to speak to the wellbeing of the framework by independently breaking down the conduct of its segments as far as disappointment probability, outcome seriousness and disappointment result likelihood. The creators expressed how the mix of the fuzzy sets hypothesis (Zadeh, 1965) in chance appraisal models is a decent method to manage vulnerability issues. In addition, fuzzy sets permit the presentation of verbal judgments, rather than numerical ones, which are more human interpretable, along these lines including additionally understanding in the assessment of substantial quantities of unsafe exercises. Fuzzy logic has been utilized in dealing with inaccurate and obscure data on account of its capacity to use regular dialect as far as etymological factors. Sugeno (1974) 
exhibited the hypothesis of fuzzy measures and fuzzy integrals as intends to express fuzzy frameworks and further proposed to utilize his hypothesis in demonstrating subjective human assessment process. Henceforth, subjective human evaluations can be preferable approximated utilizing fuzzy measures over utilizing the added substance ones. Utilizations of fuzzy sets inside the field of decision-production have, generally, comprised of expansions or fuzzifications of the established hypotheses of decision-production. While decision-maiking under states of hazard and vulnerability have been displayed by probabilistic decision hypotheses and by diversion speculations, fuzzy decision speculations endeavor to manage the dubiousness or fluffiness intrinsic in subjective or loose conclusions of inclinations, limitations, and objectives.

3. FUZZY EXPERT SYSTEMS: A fuzzy expert system is an expert system that uses fuzzy logic instead of Boolean logic. Fuzzy expert systems are the most common use of fuzzy logic. They are used in several wide-ranging fields, including:

1) Linear and nonlinear control.

2) Pattern recognition.

3) Financial systems.

How does Fuzzy Logic Works Fuzzy Logic requires some numerical parameters with a specific end goal to work, for example, what is viewed as huge mistake and huge rate-of-progress of-blunder, yet correct estimations of these numbers are typically not basic unless exceptionally responsive execution is required in which case exact tuning would decide them. For instance, a straightforward temperature control framework could utilize a solitary temperature input sensor whose information is subtracted from the order flag to process "blunder" and after that time-separated to yield the mistake slant or rate-of progress ofblunder, in the future called "mistake dab". Blunder may have units of degs $\mathrm{F}$ and a little mistake thought to be $2 \mathrm{~F}$ while an extensive mistake is $5 \mathrm{~F}$. The "blunder dab" may then have units of degs/min with a little mistake dab being $5 \mathrm{~F} / \mathrm{min}$ and a substantial one being $15 \mathrm{~F} / \mathrm{min}$. These qualities don't need to be symmetrical and can be "changed" once the framework is working with a specific end goal to streamline execution. By and large, FL is forgiving to the point that the framework will likely work the first run through with no tweaking.

\section{FUZZY REASONING OR LOGIC OPERATIONS:}

Fuzzy Set Theory characterizes Fuzzy Operators on Fuzzy Sets. The issue in applying this is the fitting Fuzzy Operator may not be known. Consequently, Fuzzy logic normally utilizes IF-THEN guidelines, or develops that are proportional, for example, fuzzy affiliated networks. Principles are typically communicated in the frame: IF variable IS property THEN activity For instance, a to a great degree basic temperature controller that uses a fan may resemble this: IF temperature IS extremely chilly THEN stop fan IF temperature IS icy THEN turn down fan IF temperature IS ordinary THEN keep up level IF temperature IS hot THEN accelerate fan Notice there is no "ELSE". The greater part of the guidelines is assessed, in light of the fact that the temperature may be "frosty" and "ordinary" in the meantime to various degrees. The AND, OR, and NOT administrators of boolean logic exist in fuzzy logic, normally characterized as the base, most extreme, and supplement; when they are characterized thusly, they are known as the Zadeh administrators, since they were first characterized all things considered in Zadeh's unique papers.

So for the fuzzy variables $\mathrm{x}$ and $\mathrm{y}$ :

NOT $x=(1-\operatorname{truth}(x))$

$\mathrm{x}$ AND $\mathrm{y}=\operatorname{minimum}(\operatorname{truth}(\mathrm{x}), \operatorname{truth}(\mathrm{y}))$

$x$ OR $y=\operatorname{maximum}(\operatorname{truth}(\mathrm{x}), \operatorname{truth}(\mathrm{y}))$

There are also other operators, more linguistic in nature, called hedges that can be applied. These are generally adverbs such as "very", or "somewhat", which modify the meaning of a set using a mathematical formula.

Utilization OF FUZZY LOGIC: There are a few fields where fuzzy logic framework utilizes as given beneath:

1) Air conditioners

2) The Massive motor utilized as a part of the Lord of the Rings

3) Films, which helped immense scale armed forces make irregular,

4) Yet methodical developments;

5) Cameras 
6) Digital picture handling, for example, edge detection;

7) Rice cookers

8) Dishwashers

9) Elevators

10) Washing machines and other home apparatuses

11) Video diversion

12) Artificial intelligence

13) Language channels on message sheets and talk spaces for sifting through hostile content

14) Pattern acknowledgment in Remote Sensing

15) Polarimetric climate radar;

16) Fuzzy logic has likewise been fused into some microcontrollers and microchips; Mineral Deposit estimation

\section{REFERENCES :}

1) Zadeh, L.A., (1965), Fuzzy sets. Information Control 8, 338-353.

2) Wang, J., Yang, J.B., Sen, P., (1995), Safety analysis and synthesis using fuzzy sets and evidential reasoning. Reliability Engineering and System Safety 47, 103-118.

3) Ghotb F, Warren L.(1995), A case study comparison of the analytic hierarchy process and fuzzy decision methodology. Eng Econ.40(3):233-47.

4) Zeng J, An M, Smith NJ.(2007), Application of a fuzzy based decision making methodology to construction project risk assessment. Int J Project Manage, 25:589-600.

5) Sugeno (1974) M. Theory of fuzzy integrals and its application. Tokyo Institute of Technology, Doctoral dissertation.

6) J.G. Klir,(1990) (special issue Editor), Int. J. Gen. Sys. 17.

7) L.A. Zadeh, Int. J. Gen. Sys. 17 (1990) 95. International Research Journal of Engineering and Technology (IRJET) e-ISSN: $2395 \quad-0056$ Volume: 02 Issue: 08 | Nov-2015 www.irjet.net pISSN: 2395-0072 (C) 2015, IRJET ISO 9001:2008 Certified Journal Page 746

8) D. Dubois, H. Prade,(1980), Fuzzy Sets and Systems: Theory and Applications, Academic Press, New York.

9) H.-J. Zimmermann,(1985), Fuzzy Set Theory and Its Applications, Kluwer.

10) R.R. Yager,(1982), Fuzzy Sets and Possibility Theory, Pergamon Press, Oxford. 